Article

\title{
Heat Wave Events over Georgia Since 1961: Climatology, Changes and Severity
}

\author{
Ina Keggenhoff ${ }^{1, *}$, Mariam Elizbarashvili ${ }^{2}$ and Lorenz King ${ }^{1}$ \\ 1 Department of Geography, Justus-Liebig-University Giessen, Senckenbergstrasse 1, 35390 Giessen, \\ Germany; E-Mail: lorenz.king@geogr.uni-giessen.de \\ 2 Department of Geography, Ivane Javakhishvili Tbilisi State University, 1 Chavchavdze Avenue, \\ 0179 Tbilisi, Georgia; E-Mail: mariam.elizbarashvili@tsu.ge \\ * Author to whom correspondence should be addressed; \\ E-Mail: ina.keggenhoff@geogr.uni-giessen.de; Tel.: +49-641-993-6265; Fax: +49-641-993-6259.
}

Academic Editor: Alessandro Pezzoli

Received: 27 February 2015 / Accepted: 30 March 2015 / Published: 16 April 2015

\begin{abstract}
The Caucasus Region has been affected by an increasing number of heat waves during the last decades, which have had serious impacts on human health, agriculture and natural ecosystems. A dataset of 22 homogenized, daily maximum ( $\mathrm{T}_{\max }$ ) and minimum $\left(\mathrm{T}_{\min }\right)$ air temperature series is developed to quantify climatology and summer heat wave changes for Georgia and Tbilisi station between 1961 and 2010 using the extreme heat factor (EHF) as heat wave index. The EHF is studied with respect to eight heat wave aspects: event number, duration, participating heat wave days, peak and mean magnitude, number of heat wave days, severe and extreme heat wave days. A severity threshold for each station was determined by the climatological distribution of heat wave intensity. Moreover, heat wave series of two indices focusing on the 90th percentile of daily minimum temperature (CTN90p) and the 90th percentile of daily maximum temperature (CTX90p) were compared. The spatial distribution of heat wave characteristics over Georgia showed a concentration of high heat wave amplitudes and mean magnitudes in the Southwest. The longest and most frequently occurring heat wave events were observed in the Southeast of Georgia. Most severe heat wave events were found in both regions. Regarding the monthly distribution of heat waves, the largest proportion of severe events and highest intensities are measured during May. Trends for all Georgia-averaged heat wave aspects demonstrate significant increases in the number, intensity and duration of low- and high-intensity heat waves. However, for the heat wave mean magnitude no change was observed. Heat wave trend
\end{abstract}


magnitudes for Tbilisi mainly exceed the Georgia-averages and its surrounding stations, implying urban heat island (UHI) effects and synergistic interactions between heat waves and UHIs. Comparing heat wave aspects for CTN90p and CTX90p, all trend magnitudes for CTN90p were larger, while the correlation between the annual time-series was very high among all heat wave indices analyzed. This finding reflects the importance of integrating the most suitable heat wave index into a sector-specific impact analysis.

Keywords: heat waves; heat wave severity; Excess Heat Factor; Georgia; Southern Caucasus

\section{Introduction}

Heat waves are among the most threatening meteorological hazards related to global warming posing impacts to society, economy and ecology. Effects of heat waves can include an increase in morbidity and mortality rates (e.g., [1-5]), a rising stress on agricultural resources (e.g., [6,7]) and a strain on infrastructure (e.g., [8]). According to the Intergovernmental Panel on Climate Change (IPCC) anthropogenic influences on climate since the mid-20th century resulted in a change of frequency and intensity of daily temperature extremes and doubled the probability of occurrence of heat waves in some regions of the world [9] and the global averaged frequency, duration and intensity of heat waves are projected to increase [10-13]. The severe heat waves during the years 2001, 2003, 2006 and 2007 in Europe, and Russia in 2010, and their impacts have been investigated in various studies [14-21]. The fact that in West Asia heat waves are likely to increase in frequency and/or duration, makes it even more important to investigate observed heat wave changes with special regards to regional impacts, the communities involved, and the climatic fields affected [13]. Georgia is located in the Southern Caucasus Region between $41^{\circ}-44^{\circ} \mathrm{N}$ and $40^{\circ}-47^{\circ} \mathrm{E}$ at the border of Europe and Asia. Although it covers a small area of $69,700 \mathrm{~km}^{2}$, the country's physiographic and climatic conditions are very diverse. The relief declines from the Greater Caucasus Range in the North and the Southern Caucasus towards Transcaucasia, which stretches from the Black Sea coast in the West to the Eastern Steppe, near the Caspian Sea in the East. The Surami mountain chain divides Transcaucasia into eastern and western lowlands. While the west of Georgia is characterized by mild winters and hot summers with mean annual air temperatures of 13 to $15{ }^{\circ} \mathrm{C}$ and high annual precipitation values (1200-2400 mm), the climate in eastern Georgia is continental with much lower annual precipitation (500-600 $\mathrm{mm}$ in the lowlands) and a mean temperature between $10-13{ }^{\circ} \mathrm{C}$. In the mountainous areas mean temperature covers a range of -5 to $10{ }^{\circ} \mathrm{C}$ and precipitation varies from $800-1400 \mathrm{~mm}$ [22]. According to findings by [23] Georgia experienced pronounced summer warming trends for monthly minimum and maximum temperature means and extremes, whereas warm extremes show larger trends than cold extremes. Moreover, the trend for warm spells was observed to be significantly increasing since the 1960s. Heat waves in Georgia are one of the most common natural hazards observed and cause increasing human health impacts and economic losses [24]. Most vulnerable groups to severe heat waves can be characterized by poor health, high age and/or pronounced social isolation [25]. The rapid increase of the population and urbanization in Georgia and its strong dependence on agricultural production might amplify these negative effects. Tbilisi, Georgia's main capital is by far the most populated city in Georgia, with over one million 
inhabitants and a rapid rising number of residents. Particularly, urban regions are exposed to more frequent heat wave events, due to the urban heat island effect and synergistic interactions between heat waves and urban heat islands, such as the lack of surface moisture in urban areas, the low wind speed associated with heat waves, the increase in the ambient temperatures and the difference between urban and rural temperatures [26]. According to [27-30], who investigated recent and future heat wave changes in the East Mediterranean and Middle East (EMME) region, the health risk factor due to the projected increase in the number of heat waves, the decrease in precipitation and rising air pollution, will increase, particularly in urban areas. Heat wave impacts are currently under-reported in Georgia and information on morbidity, mortality and economic consequences are difficult to assess. During the last decades Georgia made great efforts in data recovery and monitoring extreme events and their impacts. Currently, 13 meteorological stations and 20 meteorological posts measuring temperature minimum and maximum and precipitation are working on the territory of Georgia [31]. In the course of data recovery and digitalization, the National Environmental Agency of Georgia (NEA) kindly contributed metadata to this study giving information about observation periods, and changes of locations of meteorological stations and post. In past studies most heat wave indices are defined by temperature exceeding a fixed or percentile threshold for a given period, consider maximum or minimum and focus on consecutive or single days where defined conditions above the threshold persist [14,19,32,33]. A common definition of heat waves in scientific literature does not yet exist.

Following [34,35] the heat wave indicator in the present study is defined by three or more consecutive days above positive Excess Heat Factor conditions. The EHF considers the local geographic acclimatization to temperature, the total heat load, and the recent deviation in temperature from mean temperature and therefore provides a comparative measure of intensity, load, duration and spatial distribution of a heat wave event [25]. Moreover, indices based on the $90^{\text {th }}$ percentile for maximum temperature and the $90^{\text {th }}$ percentile for minimum temperature have been investigated to compare trends in heat wave characteristics for temperature minimum and maximum series separately. Based on [18,36] multiple heat wave aspects are studied for all three indices: the heat wave number, duration, participating days, the peak and mean magnitudes. The heat wave indices and aspects are recommended by the Commission for Climatology $(\mathrm{CCl})$ Expert Team on Climate Risk and Sector-specific Climate Indices (ET CRSCI) of the World Meteorological Organization (WMO) World Climate Programme. Three new heat wave aspects have been added to the analysis by applying a severity threshold to each time-series: the number of positive, severe and extreme heat wave days, enabling the identification of potential heat-health impacts [37]. Heat-health related morbidity and mortality based on the EHF have been investigated in various studies [11,25,36-39]. The aim of this study is to provide a better understanding of the climatology and changes in the frequency, duration and intensity of summer heat wave events over Georgia and the case study Tbilisi, as the most urbanized city in Georgia. Climatologies and trends of heat wave aspects are presented using a new databank of homogenized daily temperature series from 22 stations well distributed throughout Georgia. Section 2 describes the quality control, homogenization methods of the used observation data, the heat wave indices and aspects investigated and methods used for determining heat wave severity. The annual and seasonal climatology and annual changes in the intensity, duration and frequency of heat waves over Georgia and Tbilisi are presented and discussed in Section 3. Moreover, the five most severe heat waves over Tbilisi during 1961 and 2010 have been identified and illustrated. In Section 4 results are discussed and conclusions are summarized. 


\section{Data and Methods}

\subsection{Data Quality and Homogeneity Adjustment}

Investigating the climatology and trends on observed heat waves over Georgia 87 daily minimum and maximum temperature series over Georgia for the period 1936 to 2010 were provided by the National Environmental Agency of Georgia. The analysis period 1961-2010 was chosen to study changes in heat wave characteristics under anthropogenic influenced climate conditions as well as to optimize spatial coverage and the number of stations available for the trend analysis. During 1988, 1992, and 1993 data availability for observation data records was very low and had to be rejected from the analysis of Georgian-averaged climatologies and changes. Climatologies of all heat wave aspects over Georgia have been investigated for the normal period 1961 to 1990 . Temperature minimum and maximum series with more than $20 \%$ missing values within the analysis period were excluded. Data quality control has been carried out using the computer program RClimDex Software version 1.1 available on http://etccdi.pacificclimate.org. Data quality was tested in order to label potentially wrong values, and to reject them from the analysis. Unphysical values, such as $\mathrm{T}_{\max } \geq 70{ }^{\circ} \mathrm{C}, \mathrm{T}_{\min } \leq-50{ }^{\circ} \mathrm{C}, \mathrm{T}_{\max } \leq \mathrm{T}_{\min }$ were identified and set to missing values. Outliers were detected and rejected for daily maximum and minimum temperature exceed \pm four standard deviation. After quality control, a final number of 31 minimum and maximum temperature series were left for homogeneity testing and adjustment. During the index calculation process, the following data quality requirements have been applied in order to include as many Georgian temperature series as possible: (1) A summer value is calculated if all months are present (May to September); (2) A month is considered as complete if $\leq 3$ days are missing; (3) A station will be rejected from the analysis if more than 5 consecutive months are missing. For threshold indices, a threshold is calculated if at least $70 \%$ of data are present. For the analysis period 1961-2010, 31 temperature minimum and maximum series matched all quality criteria. Inhomogeneity of time-series was tested using the software package RHtestV3 and to adjust significant breakpoints. Metadata provided by the National Environmental Agency include information of regarding the station's name, coordinates, altitude, WMO code, observational periods, missing data during an observation period, and the station's relocation date. In order to provide reliable results on the climatology and changes in heat waves, time-series with significant breakpoints not documented in the metadata were excluded from the study. Thirty-one stations were left matching all quality criteria as described above. Seven significant breakpoints were found, whereas not more than one breakpoint per maximum or minimum time-series was detected. For two stations (Tbilisi and Gori) dates of site moves were noted within the metadata, which could be confirmed by the detected breakpoints. In this study the Quantile-Matching (QM) adjustment procedure of RHtestV3 is used to adjust daily temperature series [40,41]. Details on the homogeneity testing and adjustment procedure and parameter usage during the QM adjustment procedure are stated in [23]. The resulting homogenized daily temperature dataset comprise minimum and maximum temperature series from 22 stations for the analysis period of 1961 to 2010 (see Appendix).

\subsection{Heat Wave Indices and Characteristics}

In 2011 a "core set" of 34 descriptive sector-specific indices has been defined by the World Meteorological Organization (WMO) Commission for Climatology (CCl) Expert Team on Climate Risk 
and Sector-specific Indices (ET CRSCI) to improve decision-making for planning, operations, risk management and for adaptation to both climate change and variability. These internationally agreed indices were developed in part from the core set of indices that are developed and maintained by the Expert Team on Climate Change Detection and Indices (ETCCDI) monitoring changes in "moderate" extremes. However, the new core set of indices provide nine additional indices, such as five heat wave indices, to facilitate the use of climate information in users' decision-support systems for climate risk management and adaptation strategies [36]. All selected indices were calculated using the ClimPACT software, an R-based software provided to calculate the indices from the ET CRSCI website [42]. The present study uses the Excess Heat Factor (EHF) as heat wave index defined by [25]. Both maximum and minimum temperatures are used in this assessment. The EHF combines a measure of excess heat, the deviation from long term mean temperature, calculated with respect to the period 1961-1990, to take into account local geographic acclimatization, and heat stress, the deviation in temperature from mean temperature for the previous 30 days to measure short-term acclimatization. EHF values are calculated from a three-day mean of forecast temperatures to derive an index of heat wave intensity. Two sub-indices are combined to produce the complete EHF index. The first is a measure of significant excess heat relative to local climatic conditions, the 95 th percentile of mean temperature conditions $\left(\mathrm{EHF}_{\mathrm{sig}}\right)$ :

$$
E H I_{\text {sig }}=\left(T_{i}+T_{i+1}+T_{i+2}\right) / 3-T_{95}
$$

The second sub-index is a measure of short-term acclimatization to heat, relative to the mean temperature of the previous 30 days $\left(\mathrm{EHF}_{\mathrm{accl}}\right)$ :

$$
E H I_{a c c l}=\left(T_{i}+T_{i+1}+T_{i+2}\right) / 3-\left(T_{i-1}+\ldots+T_{i-30}\right) / 30
$$

These two indices are combined to generate the EHF index. The unit of EHF is ${ }^{\circ} \mathrm{C}^{2}$ :

$$
E H F=E H I_{\text {sig }} \times \max \left(1, E H I_{\text {accl }}\right)
$$

EHF incorporates the effect of humidity on heat tolerance indirectly, by using the mean, rather than the maximum daily temperature, in the calculation. It provides a comparative measure of intensity, load, duration and spatial distribution of a heat wave event and has a strong signal-to-noise ratio. With an increase in Excess Heat $\left(\mathrm{EHF}_{\mathrm{sig}}\right)$ and Heat Stress $\left(\mathrm{EHF}_{\mathrm{accl}}\right)$, EHF increases as a quadratic response to increasing heat load. Heat waves are defined as a period of at least three days with $E H F \geq 0$ and the combined effect of excess heat and heat stress with respect to the local climate [25]. The heat wave index EHF was selected with regards to eight heat wave aspects quantifying the intensity, frequency and duration of a heat wave event. This multi-aspect framework is based on that of [18], which was slightly extended by [11] to the following five attributes of heat wave aspects:

1. HWN - the yearly number of heat waves;

2. HWD - the length (in days) of the longest yearly event;

3. HWF - the sum of participating heat wave days per year

4. HWA - the hottest day (amplitude) of the hottest yearly event;

5. HWM - the mean event intensity averaging all participating event days

Further to these five heat wave aspects three new aspects have been included in the heat wave analysis based on the Excess Heat Factor: HWday - the number of heat wave days, HWsev- the number of severe heat wave days and HWex-extreme heat wave days. These heat wave aspects enable to 
differentiate between heat wave days, severe and extreme heat wave days and include the aspect of heat-health considering the exceedance of a station's severe EHF threshold (Section 2.3). The resulting heat wave aspects analyzed are summarized in Table 1. All eight aspects are calculated annually over the summer season, which is defined as a period from May to September (153 days).

Table 1. Heat wave aspects analyzed based on the Excess Heat Factor (EHF) with index names, definitions, and units.

\begin{tabular}{llll}
\hline ID & Heat Wave Aspect & Definition & Unit \\
\hline HWN & Heat wave number & $\begin{array}{l}\text { The annual number of summer (May-Sep) heat waves where } \\
\text { conditions persist for at least 3 consecutive days with } \\
\text { positive EHF values }\end{array}$ & $\begin{array}{l}\text { Number } \\
\text { of events }\end{array}$ \\
\hline HWD & Heat wave duration & $\begin{array}{l}\text { The length of the longest summer (May-Sep) heat wave } \\
\text { where conditions persist for at least 3 consecutive days with } \\
\text { positive EHF values }\end{array}$ & days \\
\hline HWF & Heat wave day frequency & $\begin{array}{l}\text { The total number of days each summer (May-Sep) that } \\
\text { contribute to all heat waves where conditions persist for at } \\
\text { least 3 consecutive days with positive EHF values }\end{array}$ & days \\
\hline HWM & Heat wave mean & $\begin{array}{l}\text { The hottest day of the hottest summer (May-Sep) heat wave } \\
\text { where conditions persist for at least 3 consecutive days with } \\
\text { positive EHF values }\end{array}$ & ${ }^{\circ} \mathrm{C}^{2}$ \\
\hline HWday & Heat wave days & $\begin{array}{l}\text { Average magnitude of all summer (May-Sep) heat wave } \\
\text { days where conditions persist for at least 3 consecutive days } \\
\text { with positive EHF values }\end{array}$ & ${ }^{\circ} \mathrm{C}^{2}$ \\
\hline HWsev & Heat wave severe days & $\begin{array}{l}\text { The annual number of all summer (May-Sep) heat wave } \\
\text { days with positive EHF values }\end{array}$ & days \\
\hline HWex & Heat wave extreme days & $\begin{array}{l}\text { The annual number of all severe summer (May-Sep) heat } \\
\text { wave days with positive EHF values above the station's } \\
\text { severe EHF threshold at EHF } \\
\text { station's distribution of positive EHF values) }\end{array}$ & $\begin{array}{l}\text { The annual number of all extreme summer (May-Sep) heat } \\
\text { wave days with positive EHF values that at least double the } \\
\text { station's severe EHF threshold at EHF } \\
\text { the station's distribution of positive EHF values) }\end{array}$ \\
\hline
\end{tabular}

In order to compare the differences between Georgia-averaged trends in heat wave characteristics based on temperature minimum and maximum series separately the heat wave aspects HWN (the yearly number of heat waves), HWD (the length of the longest yearly event), HWF (the sum of participating heat wave days per year), HWA (the hottest day the hottest yearly event), and HWM (the mean event intensity averaging all participating event days) based on the 90th percentile for maximum temperature (CTX90pct), the 90th percentile for minimum temperature were calculated (CTN90pct). Heat wave indices based on daily $\mathrm{T}_{\min }$ and $\mathrm{T}_{\max }$ are defined as follows:

(1) CTN90pct - the calendar day 90th percentile of daily $T_{\min }$ calculated for a five-day window centered on each calendar day in the base period,

(2) CTX90pct - the calendar day 90th percentile of daily $T_{\max }$, as described for $T_{\min }$.

The unit of CTN90pct and CTX90pct is ${ }^{\circ} \mathrm{C}$. Due to the low amount of measurable events a set of 14 time series for all three heat wave indices was used for this analysis. All trends were calculated by the non-parametric Sen's slope estimator based on Kendall's tau $(\tau)$ [43]. The annual slopes of trends were converted into slope per decade. The statistical significance has been estimated using the 
Mann-Kendall test, whereas in the present study a trend was considered to be statistically significant if it was less than or equal to a level of 5\% $[44,45]$. Station trends have only been estimated if data requirements are met as described above. Apart from trends for each individual station, trends were also averaged for all Georgian station records. These trends were calculated as the arithmetic average of the summer index values at all stations.

\subsection{Severe and Extreme Heat Waves}

In terms of heat-health, low values of EHF may be considered as uncomfortable and have no or only little impact. Severe heat wave impacts on heat-health are relatively rare, due to the local adaption capacity of the affected population based on the long-term experience to cope with heat waves of low to moderate intensity. In the present study severe heat waves are defined by an event where EHF values exceed a threshold for severity that is specific to the climatology of each location following [25]. To identify severe and extreme heat wave events during 1961 and 2010 over Georgia a severe EHF threshold for each station has been detected. Using the example of Tbilisi time series (Figure 1) it is shown that the upper end of the EHF distribution is fat-tailed which allows the identification of a threshold between more-frequent lower-intensity events and less-frequent higher intensity events.

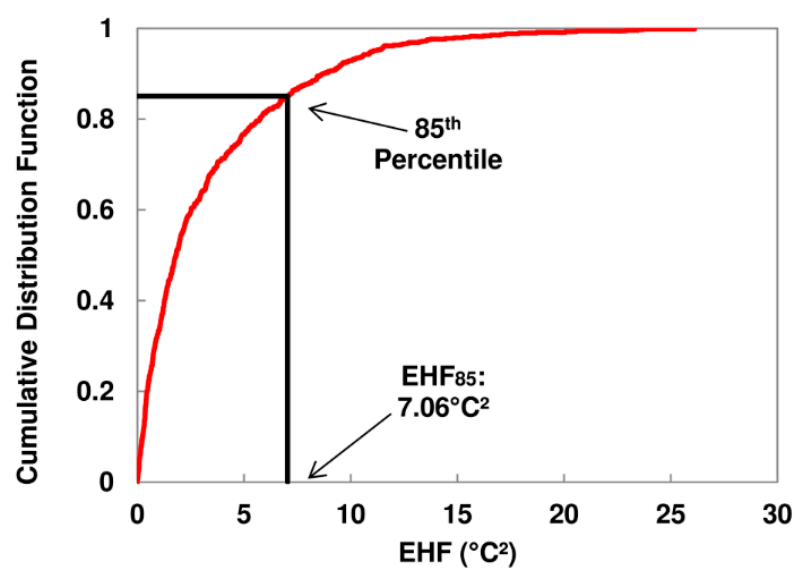

Figure 1. Determining $\mathrm{EHF}_{85}$ and severe heat wave days for Tbilisi station (1961-2010): Tbilisi cumulative distribution of positive EHF (red line) and the severe EHF threshold at the 85 th percentile (black line).

The severe EHF threshold is calculated empirically as the $85^{\text {th }}$ percentile of the distribution of positive EHF values $\left(\mathrm{EHF}_{85}\right)$ based on the observation record at a given location. This method ensures that all EHF values are truly representative of each site's climatology and avoids potential errors by modeling a distribution. Extreme heat waves are defined as an event where EHF values are well in excess of the severity threshold and result in a wide impact based on a cascade of failing systems [25]. In the present study extreme heat waves occur if an EHF value during a heat wave at least doubles the severity threshold $\left(E H F \geq 2 \times E H F_{85}\right)$. 


\section{Results and Discussion}

\subsection{Heat Wave Climatology}

In this section the climatological Georgia-average during the period 1961-1990 is investigated with respect to selected heat wave aspects.

Table 2. Georgia-averaged heat wave climatology for the period 1961-1990 for the heat wave aspects: HWN, HWD, HWF, HWA, HWM, HWday, HWsev and HWex.

\begin{tabular}{ll}
\hline Heat Wave Aspect for EHF Index & Annual Average (1961-1990) \\
\hline Heat Wave Number (no. of events) & 1.7 \\
Heat Wave Duration (days) & 5.5 \\
Heat Wave Frequency (days) & 10.4 \\
Heat Wave Amplitude $\left({ }^{\circ} \mathrm{C}^{2}\right)$ & 12.2 \\
Heat Wave Mean Magnitude $\left({ }^{\circ} \mathrm{C}^{2}\right)$ & 4.3 \\
Heat Wave Days (days) & 10.3 \\
Severe Heat Wave Days (days) & 1.3 \\
Extreme Heat Wave Days (days) & 0.3 \\
\hline
\end{tabular}

In Table 2, it is shown that the Georgia-average HWN amounts to 1.7 events/year. Highest numbers of annual events range between 1.7 and 1.9 events/year and can be found throughout the whole territory of Georgia. Lowest numbers of HWN are observed at the Western coast (1.3-1.5 events/year), while a general distribution for all heat wave numbers across Georgia does not show clear spatial patterns (Figure 2a).

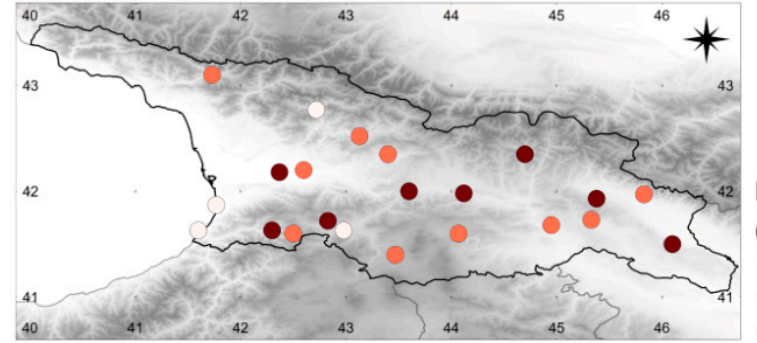

(a)

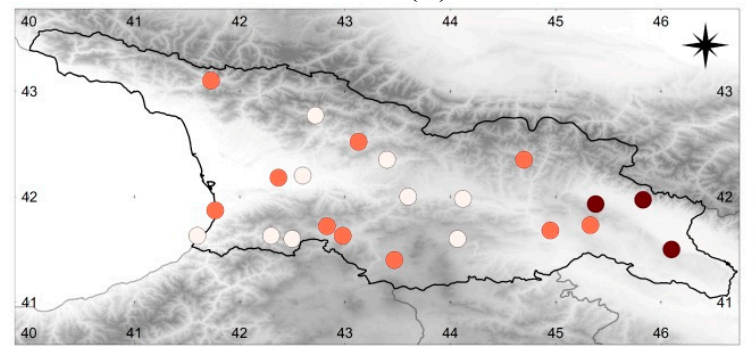

(c)

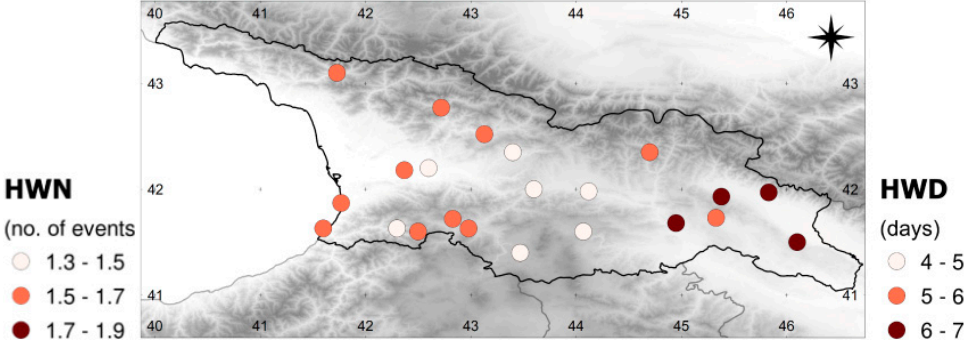

(b)

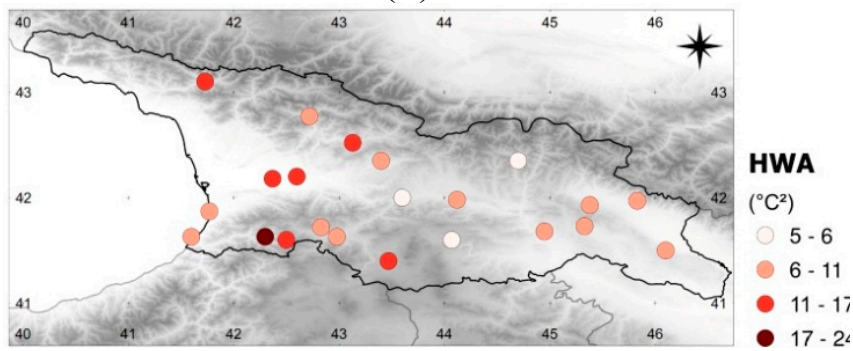

(d)

Figure 2. Cont. 


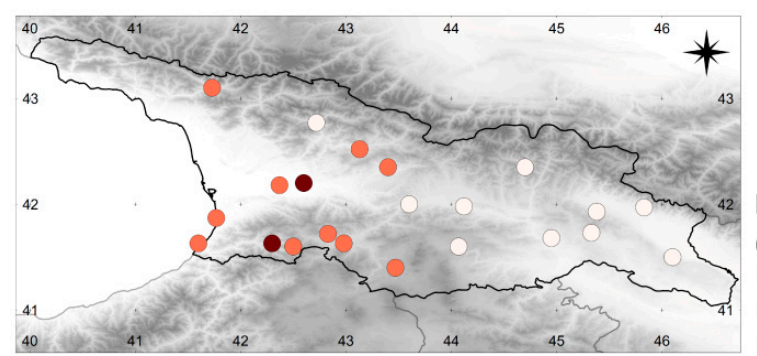

(e)

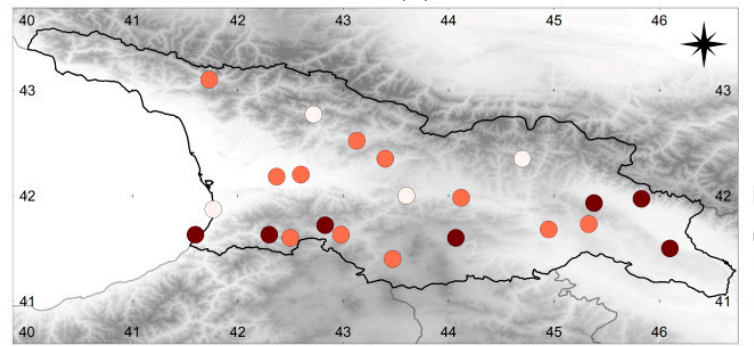

(g)

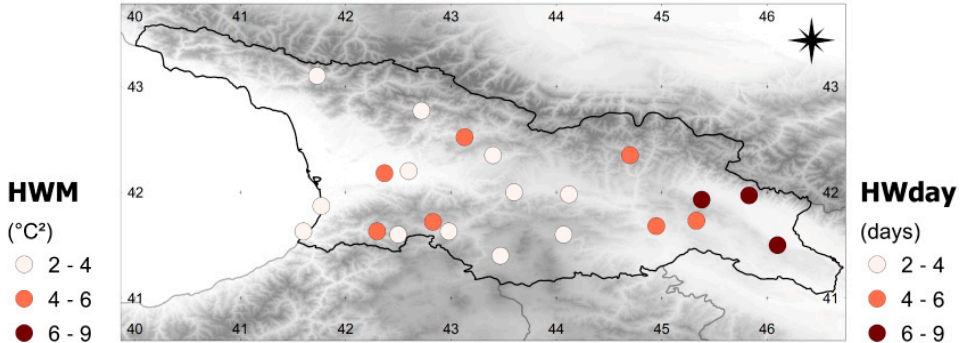

(f)

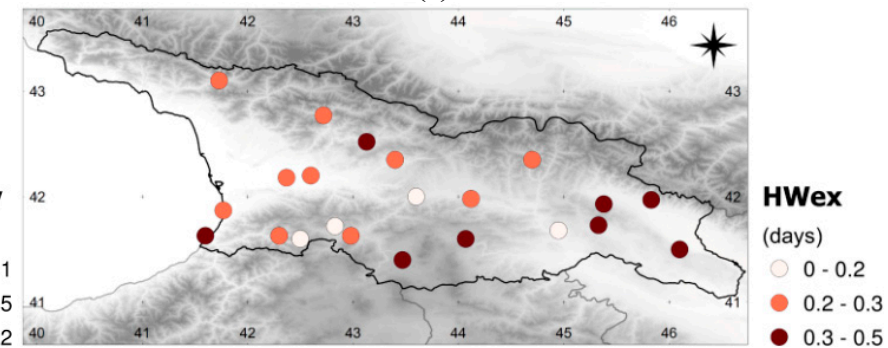

(h)

Figure 2. Station climatologies over Georgia for the period 1961-1990 and the selected heat wave aspects: (a) Heat Wave Number (no. of events); (b) Heat Wave Duration (days); (c) Heat Wave Frequency (days); (d) Heat Wave Amplitude $\left({ }^{\circ} \mathrm{C}^{2}\right)$; (e) Heat Wave Magnitude $\left({ }^{\circ} \mathrm{C}^{2}\right)$; (f) Heat Wave Days (days) and (g) Severe Heat Wave Days (days); and (h) Extreme Heat Wave Days (days).

However, spatial patterns can be found for HWD, which measures 5,5 days/year in the Georgia-average. Highest averaged values for HWD are concentrated in the southeastern dry steppe (6-7 days/year). Heat waves with a mean duration of 5 to 6 days per year are predominantly located in the Western part of Georgia. The shortest heat waves (4-5 days/year) are observed in central Georgia (Figure 2b). The Georgia-average for HWF (yearly sum of participating heat wave days) measures 10.4 days/year (Table 2). Eleven to 15 days contribute at most to all summer heat waves in Georgia. Similar to HWD, the highest HWF values can be found in the southeast, lowest values in central Georgia (9-10 days/year) (Figure 2c). HWA means measure $12.2{ }^{\circ} \mathrm{C}^{2} /$ year between 1961 and 1990 (Table 2). Highest station heat wave amplitudes per year measure $17-24^{\circ} \mathrm{C}^{2}$ averaged over Georgia. Strongest heat wave peaks are located in the western part of Georgia with highest HWA means $\left(17-25^{\circ} \mathrm{C}^{2} /\right.$ year $)$ in the southwest (Figure $2 \mathrm{~d}$ ). Similar to HWA, highest station means for HWM $\left(6-9{ }^{\circ} \mathrm{C}^{2} /\right.$ year $)$ are concentrated in the southwestern part of Georgia (Figure 2e) with a Georgia-average of $4.3{ }^{\circ} \mathrm{C}^{2} /$ year (Table 2). Lowest magnitudes $\left(2-4{ }^{\circ} \mathrm{C}^{2} /\right.$ year $)$ are predominantly found in the eastern part of Georgia. Most positive EHF values (11-12 days/year) can be found in the Southeastern part of the study area, while most severe (40-50 days/year) and extreme days (0.4-0.5 days/year) can be observed in the southeast and the southwest (Figure $2 \mathrm{f}-\mathrm{h}$ ). Georgia-averaged climatologies for HWday measure 10.3 days/year. For severe and extreme days an annual mean of 1.3 days/year and 0.3 days/year can be found, respectively (Table 2). The monthly distribution of the mean number and mean intensity (positive EHF values) of summer HWday (Heat Wave Days), HWsev (Severe Heat Wave Days) and HWex (Extreme Heat Wave Days) between 1961 and 2010 is shown in Figure 3. Highest numbers of HWday can be found in August (3.4 days/month), lowest in May (1.8 days/month). However, in the Georgia-average most HWsev and HWex occur during May with decreasing numbers toward September. The highest mean intensity for 
HWday, HWsev and HWex was observed during May at a rate of $7.0{ }^{\circ} \mathrm{C}^{2}, 16.1{ }^{\circ} \mathrm{C}^{2}$, and $23.8{ }^{\circ} \mathrm{C}^{2}$, respectively. While the heat wave aspects HWday and $\mathrm{HWsev}$ show decreasing intensities towards September, the intensity of HWex decreases until July and peaks again in September measuring $23.5^{\circ} \mathrm{C}^{2}$.

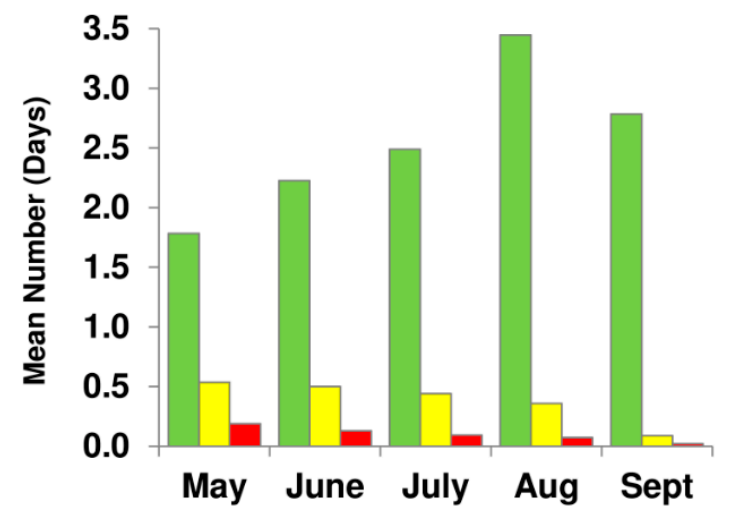

(a)

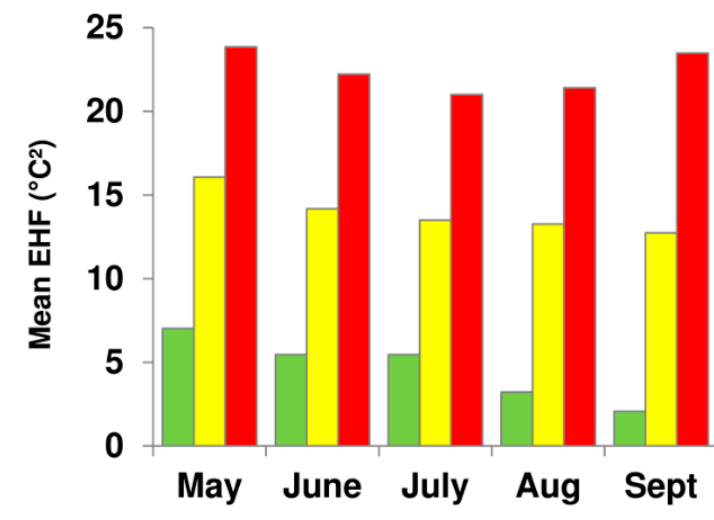

(b)

Figure 3. Seasonal distribution of (a) the mean number (days) and (b) the mean EHF value $\left({ }^{\circ} \mathrm{C}\right)$ of HWday (green bars), HWsev (yellow bars) and HWex (red bars) averaged over Georgia for the period 1961-2010.

On the whole, highest EHF intensities are spread across the lowest count of monthly EHF days during May. Regarding the heat wave aspects HWsev and HWex, highest intensities are found among the highest number of positive EHF days in May. However, lowest numbers of HWsev and HWex during September show almost the same intensity of mean EHF than in May, implying high peak amplitudes of severe and extreme heat wave days during September.

\subsection{Changes in Heat Wave Characteristics}

In this section heat wave changes in the Georgia-average during the period 1961 to 2010 are investigated.

As Table 3 shows, all trends were found significantly positive, with the exception of the annual trend for HWM (average magnitude of all yearly heat waves), which shows an insignificant trend of approximately zero. For HWN a significant increasing trend of 0.4 events/decade can be observed (Table 3). All single station trends throughout Georgia were found to be positive (Figure 4a). During the period 1961-2010, 12 of 22 stations analyzed indicate significantly positive trends. Five of them show trend magnitudes of 0.5-1 events/decade, while 10 of all stations are approximately zero, indicating that the yearly number of heat waves for these stations did not change during 1961 and 2010. For HWD (the length of the longest yearly heat wave event) a significant magnitude of 0.9 days/decade was found in the Georgia-average (Table 3). Similar to HWN, no decreasing trend could be observed throughout Georgia. Twelve stations show significant trends, of which four stations show trend magnitudes between 1 and 2 days/decade (Figure $4 b$ ). 


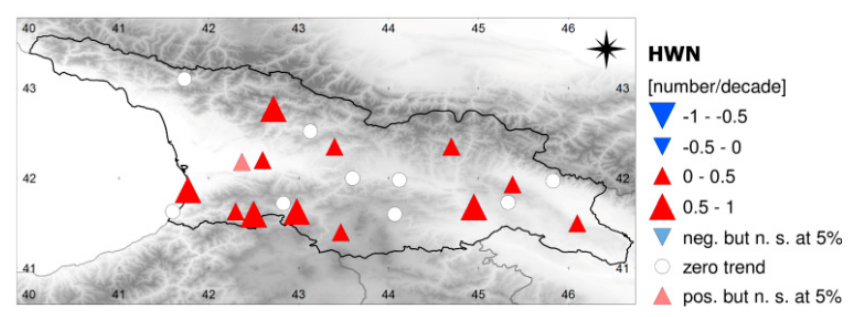

(a)
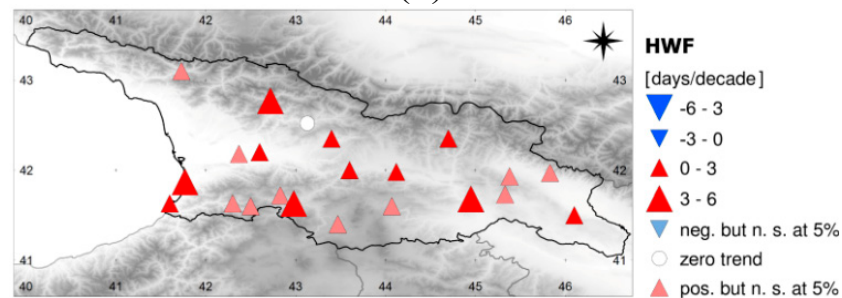

(c)

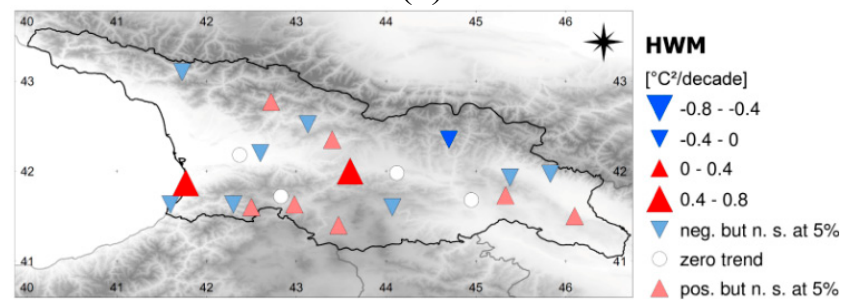

(e)

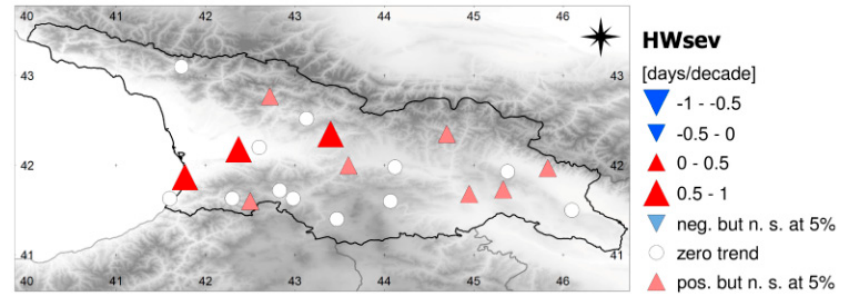

(g)

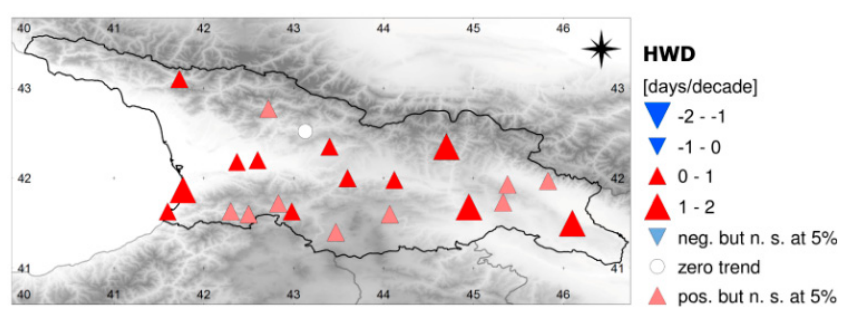

(b)

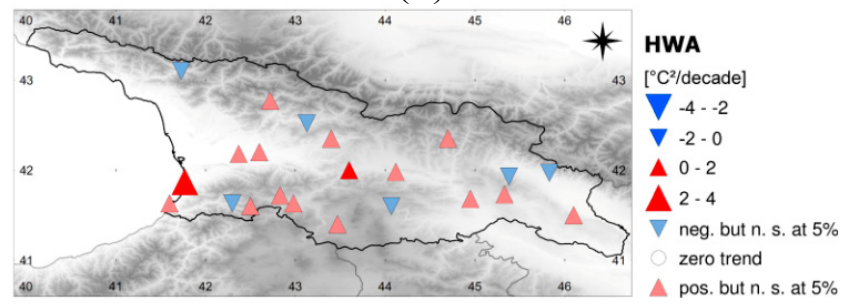

(d)

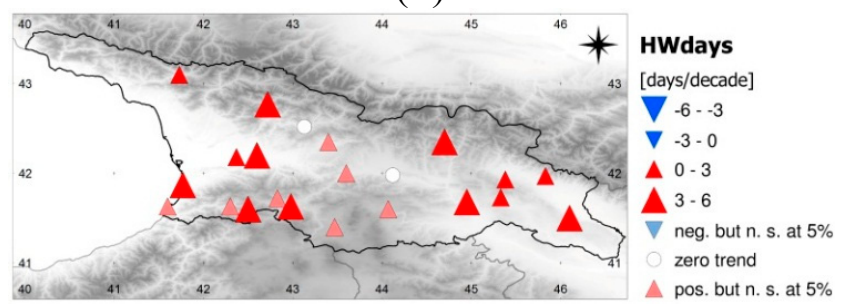

(f)

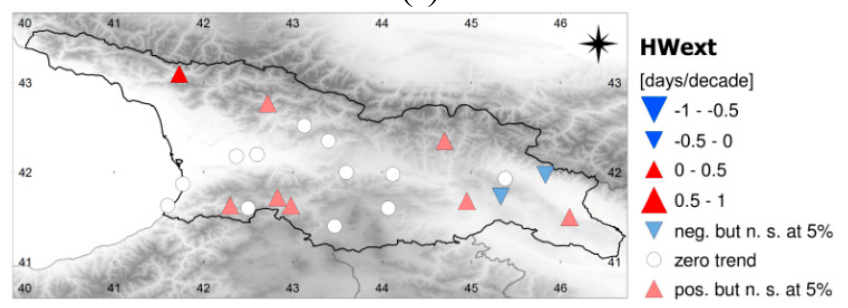

(h)

Figure 4. Station trends of selected heat wave aspects over Georgia for the period 1961-1990: (a) Heat Wave Number (no. of events); (b) Heat Wave Duration (days); (c) Heat Wave Frequency (days); (d) Heat Wave Amplitude $\left({ }^{\circ} \mathrm{C}^{2}\right)$; (e) Heat Wave Magnitude $\left({ }^{\circ} \mathrm{C}^{2}\right)$; (f) Heat Wave Days (days) and (g) Severe Heat Wave Days (days); and (h) Extreme Heat Wave Days (days). Red triangles indicate warming trends, blue indicate cooling trends. Light blue and red triangles indicate trends not significant at the 5\% level.

Table 3. Annual averaged trends for investigated heat wave aspects between 1961 and 2010 with respective confidence intervals (95\%). Trends significant at the 5\% level are indicated in bold and highlighted in green.

\begin{tabular}{ll}
\hline Heat Wave Aspect for EHF Index & Trend Magnitude/Decade $(\mathbf{1 9 6 1 - 2 0 1 0})$ \\
\hline Heat Wave Number (no. of events) & $\mathbf{0 . 4}(\mathbf{0 . 2}$ to 0.6$)$ \\
Heat Wave Duration (days) & $\mathbf{0 . 9}(\mathbf{0 . 5}$ to 1.5$)$ \\
Heat Wave Frequency $($ days) & $\mathbf{2 . 9}(1.5$ to 4.7$)$ \\
Heat Wave Amplitude $\left({ }^{\circ} \mathrm{C}^{2}\right)$ & $\mathbf{1 . 1}(\mathbf{0 . 2}$ to 2.2$)$ \\
Heat Wave Mean Magnitude $\left({ }^{\circ} \mathrm{C}^{2}\right)$ & $0.0(-0.4$ to 0.3$)$ \\
Heat Wave Days (days) & $\mathbf{3 . 3}(\mathbf{1 . 9}$ to 5.2$)$ \\
Severe Heat Wave Days (days) & $\mathbf{0 . 3 7}(\mathbf{0 . 1 4}$ to $\mathbf{0 . 7 7})$ \\
Extreme Heat Wave Days (days) & $\mathbf{0 . 0 5}(\mathbf{0 . 0 0}$ to 0.17$)$ \\
\hline
\end{tabular}


The heat wave aspect HWF (yearly sum of participating heat wave days) shows the largest trends of up to 6 days/decade during the period 1961 to 2010 (Figure 4c). Similar to HWN and HWD all station trends are increasing and stations with statistically significant trends for HWN and HWD are also statistically significant for HWF. The Georgia average trend amounts to 2.9 days/decade (Table 3). These findings are in accordance with [36], demonstrating that the high trend magnitude of HWF drives increases in HWN and HWD, as the number of heat wave days represents an influencing factor in the calculation of event length and occurrence. HWA (the averaged peak of the hottest summer day) and HWM (the average magnitude of all summer heat waves) show lower and less significant station trends. Although few negative station trends can be observed for HWA a significant positive trend of $1.1{ }^{\circ} \mathrm{C} /$ decade can be found in the Georgia average (Table 3). HWA and HWM (the average magnitude of all summer heat waves) show lower and less significant averaged station trends. For HWM an insignificant averaged trend, approximating zero, can be observed, indicating no change of the mean magnitude of all summer heat waves during 1961 and 2010. However, regarding Georgia-averaged HWday (positive EHF days), HWsev (severe days) and HWex (extreme days) significant increasing trends could be found. For HWday all station trends are increasing and a high proportion of 13 stations show significant trends measuring up to 6 days/decade. Trends with the highest magnitudes are predominantly located in Eastern and Western Georgia (Figure 4f). In the Georgia-average a significant positive trend of 3.3 days/decade for HWday was observed. Severe days and extreme days increased at a significant rate of 0.4 days/decade and 0.05 days/decade, respectively (Table 3). Additionally, for HWsev all station trends are increasing, while only three stations show significant trends. Due to the low number of observed extreme days per year, trends for HWex show either insignificant slopes throughout Georgia or trends approximating zero. There are predominantly positive trends noted, only two station trends were found to be insignificantly negative (Figure $4 \mathrm{~h}$ ). In order to be able to compare trends between temperature minimum and maximum series separately and to investigate which of the series shows more response to trends in heat wave aspects, trends for the $90^{\text {th }}$ percentile maximum temperature (CTX90pct), the 90th percentile minimum temperature were calculated (CTN90pct). It is shown, that all trends for CTN90pct demonstrate a higher magnitude than for CTX90pct, which corresponds to global heat wave observations [11].

As shown in Table 3, heat wave trends for HWN measure a significant increase of 0.50 heat wave events/decade averaged over Georgia, regarding the heat wave index CTN90pct. However, for CTX90pct a significant trend at a rate of 0.41 events/decade can be observed, suggesting that consecutive days of extreme high temperature maxima are less common over Georgia than consecutive nights of extreme temperature minima. Regarding the heat wave aspect HWD, a significant increase for both indices could be found, while CTN90p shows a higher trend magnitude averaged over Georgia ( 0.65 days/decade). Similar to results for the heat wave index EHF Georgia-averaged trends for HWF are of higher magnitude compared to HMN and HWD. CTN90pct measures a significant positive trend of 2.8 days/decade. For CTX90pct a lower trend of 1.8 days/decade can be observed. Additionally, for HWA and HWM the index CTN90pct shows a higher trend magnitude throughout Georgia, than CTX90pct. CTN90pct-HWA and CTN90pct-HWM measure significant increasing trends of $0.53{ }^{\circ} \mathrm{C} /$ decade and $0.32{ }^{\circ} \mathrm{C} /$ decade, respectively. For CTX90pct-HWA and CTX90pct-HWM insignificant positive trends were observed.

Figure 5 shows, that although the quantitative observations of the annual values and trend magnitudes vary for all three indices (Table 4), the annual time-series show qualitatively similar patterns among 
each of the three indices. A quantitative comparison cannot be conducted, due to the different number of stations used for the analysis on heat wave indices EHF and CTN90pct/CTX90pct.

Table 4. Georgia-averaged trends in CTN90pct and CTX90pct between 1961 and 2010 with respective confidence intervals (95\%). Trends significant at the 5\% level are indicated in bold and highlighted in green.

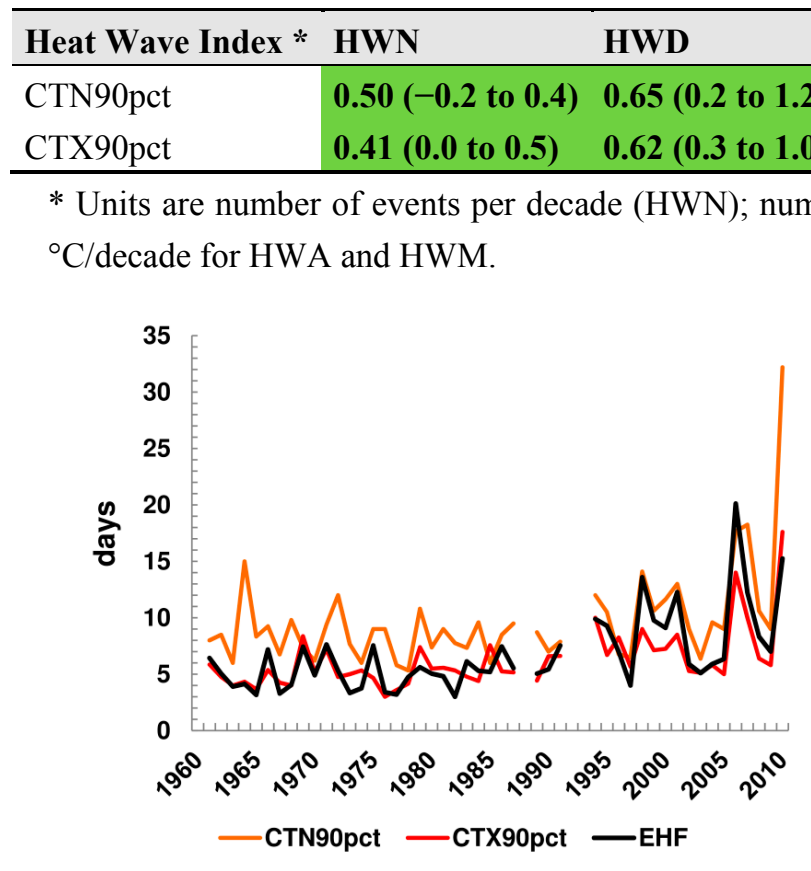

(a)

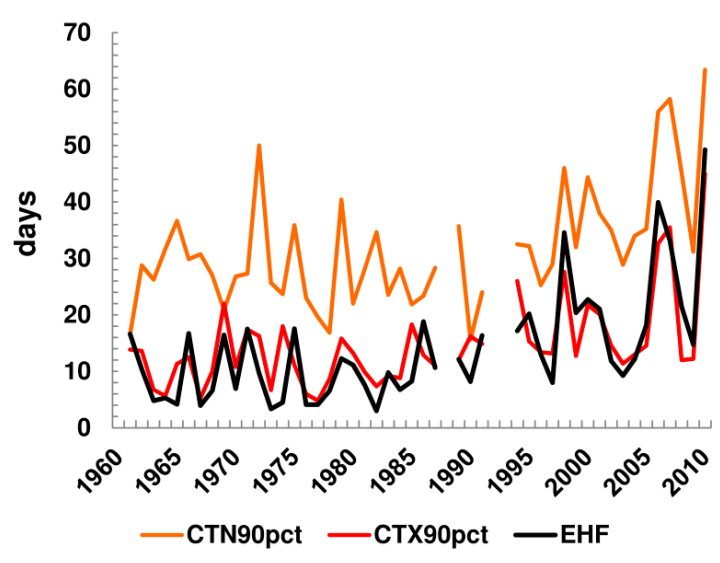

(b)

Figure 5. Comparison of annual (a) Heat Wave Duration and (b) Heat Wave Frequency for heat wave indices EHF, CTN90pct and CTX90pct during the period 1961-2010.

\subsection{Severe Heat Waves over Tbilisi}

In this section the climatology and changes in heat waves over Tbilisi station have been investigated, considering the city as an urban heat island. Moreover, the five most severe heat waves between 1961 and 2010 have been identified and illustrated.

Tbilisi experiences by far the highest trend magnitudes for all summer temperature variables analyzed compared to the Georgian mean, as well as the surrounding stations (not shown). As shown in Table 5, summertime minimum and maximum temperature averages $16^{\circ} \mathrm{C}$ and $27.4{ }^{\circ} \mathrm{C}$, respectively. The annual summer trends measure $0.32{ }^{\circ} \mathrm{C} /$ per decade for $\mathrm{T}_{\min }$ and $0.38^{\circ} /$ decade for $\mathrm{T}_{\max }$. Comparing these trends with the surrounding neighboring stations (not shown) or the Georgian-averages for summertime temperature minimum $\left(0.20^{\circ} \mathrm{C} /\right.$ decade $)$ and maximum $\left(0.31^{\circ} \mathrm{C} /\right.$ decade $)$, Tbilisi shows pronounced high trend magnitudes for $\mathrm{T}_{\min }$ and $\mathrm{T}_{\max }$ and a lower temperature variability. Moreover, for warm nights a much higher trend magnitude $\left(3.4{ }^{\circ} \mathrm{C} /\right.$ decade) is observed during summer than for warm days. In addition, compared to its neighboring stations Tbilisi shows a higher trend magnitude (not shown). Regarding Tbilisi's heat wave climatology the city shows a HWN value of 0.7 events/year, the mean heat wave duration measures 6.2 days/year and 11.0 days participate in yearly heat wave events. The peak and mean magnitude for Tbilisi averages $8.2{ }^{\circ} \mathrm{C}^{2} /$ year and $3.2{ }^{\circ} \mathrm{C}^{2} /$ year, respectively. For the 
number of heat wave days a mean value of 10.9 days/year could be found, while the climatologies for severe heat wave days (extreme heat wave days) measure 1.2 days/year ( 0.1 days/year). While Tbilisi shows lower means for HWA and HWM, it demonstrates similar mean climatological values for HWN, HWday, HWsev, and highly exceeds the Georgia-averages for the heat wave aspects HWD and HWF (Tables 2 and 3). Figure 6 shows the annual numbers of heat wave days, severe and extreme heat wave days. It is notable that the largest proportion of low- and high-intensity heat wave days can be found in the last 20 decades. An increasing number of heat waves of 0.7 events/decade were observed, the heat wave length increased by 1.0 days/decade and the trend for HWF measured 2.9 days/decade. Additionally, for HWA $\left(0.9^{\circ} \mathrm{C}^{2} /\right.$ decade) and HWday (5.5 days/decade) Tbilisi station shows a higher trend magnitude, than the Georgia averages and its neighboring stations (not shown). However, for the number of severe heat wave days Tbilisi shows a slightly lower trend magnitude ( 0.32 days/decade) compared to the Georgia-average. For HWM there is a trend measured approximating zero. Due to the low number of extreme heat wave days distributed over 50 summers the trend magnitude for HWex was not denoted.

Table 5. Climatology and annual trends for summer $T_{\min }$ and $T_{\max }$, temperature extremes and selected heat wave aspects at Tbilisi, 1961 and 2010. Trends and respective confidence intervals (95\%) significant at the 5\% level are indicated in bold and highlighted in green.

\begin{tabular}{|c|c|c|}
\hline Parameter & Annual Average (1961-1990) & Annual Trend/Decade \\
\hline $\mathrm{T}_{\min }\left({ }^{\circ} \mathrm{C}\right)$ & 16.0 & $0.32(0.22$ to 0.43$)$ \\
\hline $\mathrm{T}_{\max }\left({ }^{\circ} \mathrm{C}\right)$ & 27.4 & $0.38(0.18$ to 0.57$)$ \\
\hline $\mathrm{TN} 90 \mathrm{p}\left({ }^{\circ} \mathrm{C}\right)$ & 10.3 & $3.4(2.3$ to 5.0$)$ \\
\hline $\mathrm{TX} 90 \mathrm{p}\left({ }^{\circ} \mathrm{C}\right)$ & 10.7 & $2.7(1.2$ to 4.3$)$ \\
\hline HWN (no. of events) & 1.7 & $0.7(0.3$ to 1.1$)$ \\
\hline HWD (days) & 6.2 & $1.0(0.3$ to 1.8$)$ \\
\hline HWF (days) & 11.0 & $4.3(1.6$ to 6.7$)$ \\
\hline HWA $\left({ }^{\circ} \mathrm{C}^{2}\right)$ & 8.2 & $0.9(-0.2$ to 2.2$)$ \\
\hline $\mathrm{HWM}\left({ }^{\circ} \mathrm{C}^{2}\right)$ & 3.2 & $0.0(-0.4$ to 0.5$)$ \\
\hline HWday (days) & 10.9 & $5.5(2.8$ to 7.1$)$ \\
\hline HWsev (days) & 1.2 & $0.32(0.0$ to 1.1$)$ \\
\hline HWex (days) & 0.1 & $\mathrm{n} / \mathrm{a}$ \\
\hline
\end{tabular}

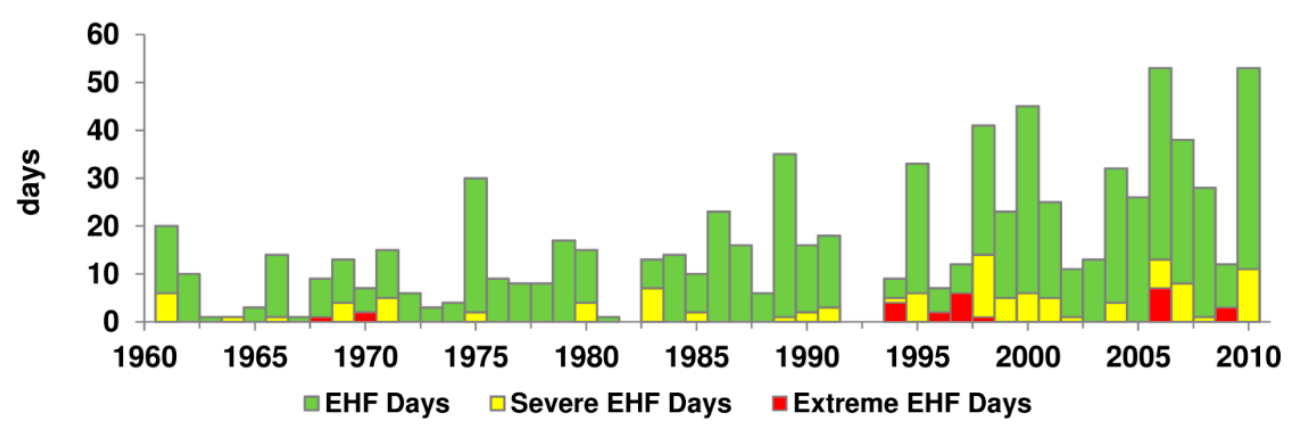

Figure 6. The annual number of heat wave days (green bars), severe heat wave days (yellow bars) and extreme heat wave days (red bars) at Tbilisi station, 1961-2010. 
Table 6. Top ranked severe heat waves measured at Tbilisi station during 1961 and 2010 listed by year: Rank, peak day of event (Date), peak EHF value $\left({ }^{\circ} \mathrm{C}^{2}\right)$, accumulated and average heat load $\left({ }^{\circ} \mathrm{C}^{2}\right)$ and EHF event duration (days). Tbilisi's severe EHF threshold accounts for $7.06\left({ }^{\circ} \mathrm{C}^{2}\right)$.

\begin{tabular}{lllllll}
\hline Year & Rank & Date & Peak EHF $\left({ }^{\circ} \mathbf{C}^{\mathbf{2}}\right)$ & Heat Load $\left({ }^{\circ} \mathbf{C}^{2}\right)$ & Average Heat Load $\left({ }^{\circ} \mathbf{C}^{2}\right)$ & EHF Event Duration (Days) \\
\hline 1971 & 2 & 6 May & 26.1 & 78 & 12.9 & 6 \\
1995 & 3 & 24 May & 23.7 & 103 & 12.9 & 8 \\
1997 & 5 & 10 May & 17.9 & 57 & 11.3 & 5 \\
1998 & 4 & 31 Aug & 20.1 & 147 & 10.5 & 14 \\
2007 & 1 & 28 May & 36.9 & 203 & 20.3 & 10 \\
\hline
\end{tabular}
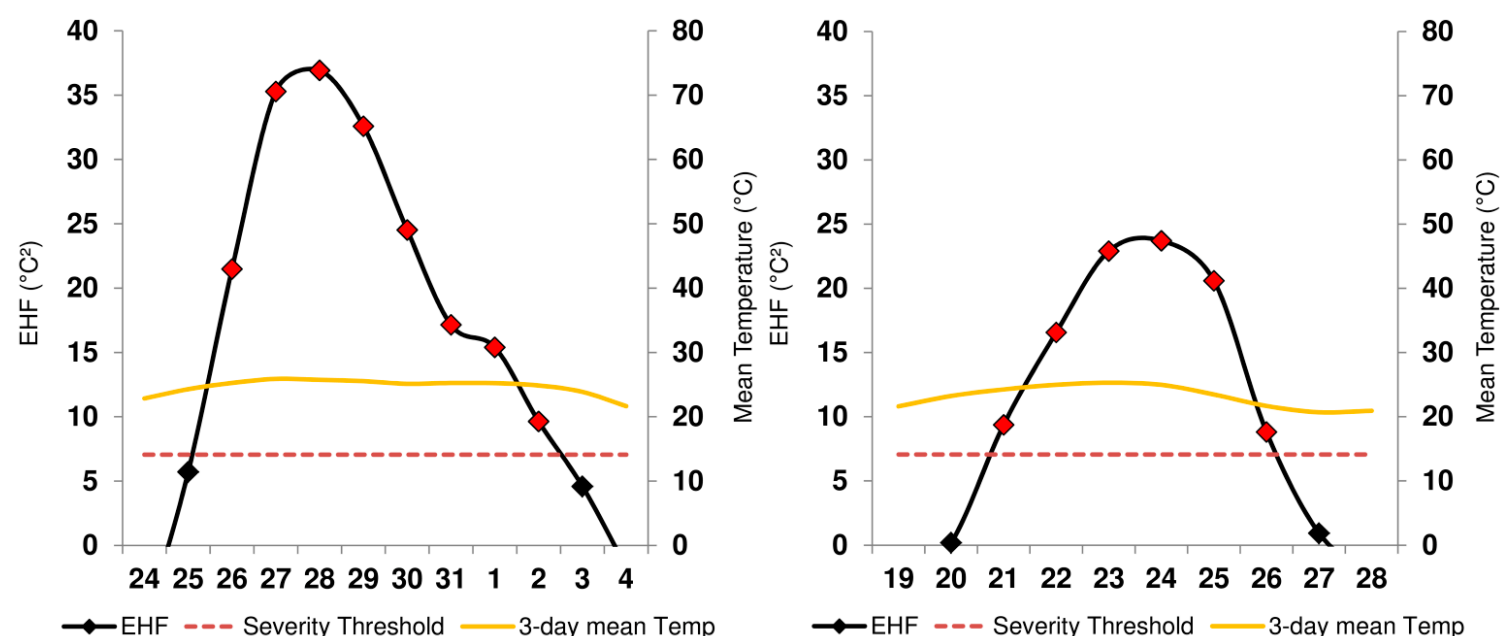

(a)

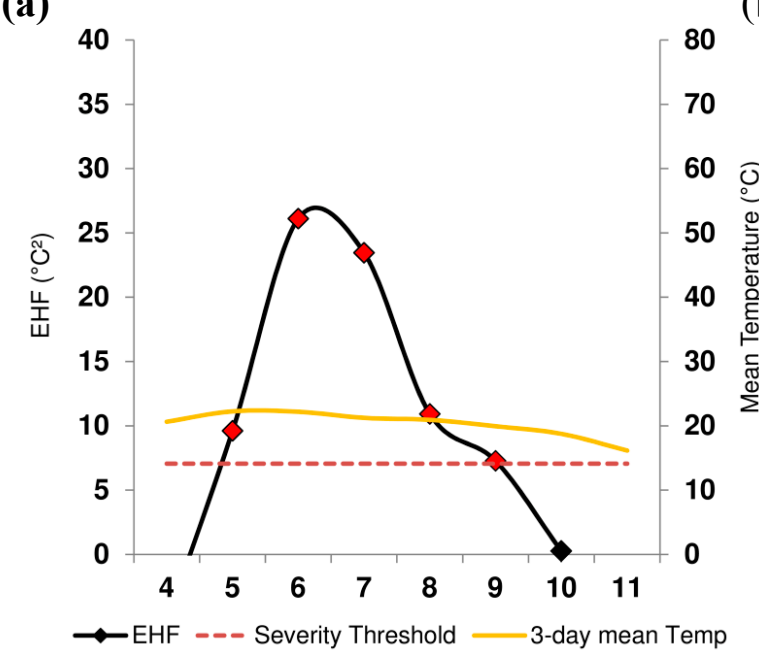

(b)

(c)

Figure 7. The three most severe summer heat wave events over Tbilisi during 1961 and 2010: Observed daily EHF values and severity threshold (dashed red line) during May 2007 (a); May 1971 (b) and May 1995 (c). Red dots indicate EHF values above the station's severity threshold $\left(\mathrm{EHF}=7.06^{\circ} \mathrm{C}^{2}\right)$. The three-day-averaged daily mean temperature (yellow line) is superimposed. 
Table 6 presents the five most severe heat wave events measured at Tbilisi station between 1961 and 2010 and their intensity (peak EHF value, ${ }^{\circ} \mathrm{C}^{2}$ ), EHF event duration (days) and accumulated heat load $\left({ }^{\circ} \mathrm{C}^{2}\right)$. The accumulated heat load is defined as the sum of the consecutive positive EHF values. By means of comparisons of international extreme heat wave events and their impacts, the peak heat load (highest EHF value) over a station's severe EHF threshold represents the most crucial indicator determining the severity of a single station heat wave $[1,25]$.

It is notable that during 1961 and 2010 four of five top-ranked severe heat wave events were found in the second half of the analysis period. The highest peak EHF value observed was measured between 25 May and 3 June 2007 . The EHF value of $36.9^{\circ} \mathrm{C}^{2}$ is over six times the magnitude of Tbilisi's severe EHF threshold $\left(7.1^{\circ} \mathrm{C}^{2}\right)$, which classifies this heat wave as an extreme event. The high average heat load and EHF event duration of eight severe days result in a huge accumulated heat load $\left(203^{\circ} \mathrm{C}^{2}\right)$ and impose high amplitudes of heat stress on the population, and other affected sectors (Figure 7a). The 1971 EHF time series shows Tbilisi's second ranked extreme heat wave. The peak magnitude for this event is almost four times the severe EHF threshold $\left(26.2^{\circ} \mathrm{C}\right)$. Figure $7 \mathrm{~b}$ shows a short period of positive EHF values with a relatively high average heat load of $12.9^{\circ} \mathrm{C}^{2}$ during the heat wave. The third ranked peak heat load observed $\left(23.7^{\circ} \mathrm{C}^{2}\right)$ was measured in 24 May 1995 and is over three times the magnitude of Tbilisi's severe EHF threshold. It was found among six severe heat wave days (Figure 7c). The fourth highest classified heat wave event observed at Tbilisi station occurred in August 1998. The event peak of $20.1^{\circ} \mathrm{C}$ is six to seven times the magnitude of Tbilisi's severe EHF threshold (Table 6) and is one of 14 heat wave days and nine consecutive severe EHF days (not shown). The fifth ranked peak EHF event of $17.9^{\circ} \mathrm{C}^{2}$ exceeds the station's severe EHF threshold by circa 2.5 times.

\section{Discussion and Conclusions}

This study analyzed climatology and changes in summer heat wave events over Georgia since the 1960s using a new dataset of daily minimum and maximum temperature series. The data was carefully quality controlled and homogeneity was tested using the software RClimDex 1.1. Metadata could be used to identify the date of breakpoints in a time-series. Inhomogeneous time-series could be adjusted using RHVtest 4 . For the investigation of heat wave climatology, changes and single severe single heat waves over Georgia and at Tbilisi station the Excess Heat Factor was, chosen a combined indicator of excess heat and heat stress and comparative a measure of intensity, load, duration and spatial distribution of a heat wave event. The EHF was analyzed with respect to eight heat wave aspects: the yearly number of heat waves (HWN), length of the longest yearly event (HWD), the yearly sum of participating heat wave days (HWF), the hottest day of hottest yearly event (HWA), and the average magnitude of all yearly heat waves (HWM). Three new heat wave aspects have been applied to the study: the number of heat wave days $\left(\mathrm{HW}_{\text {day }}\right)$, the number of severe heat wave days $\left(\mathrm{HW}_{\text {sev }}\right)$ and extreme heat wave days $\left(\mathrm{HW}_{\mathrm{ex}}\right)$ to allow a differentiated assessment of the spatial and temporal characteristics of lowintensity, severe and extreme heat waves. Severe and extreme heat waves have been detected applying a threshold, the 85th percentile of the distribution of positive EHF values, to each station. This multiaspect heat wave analysis provides a more profound study of heat wave changes in Georgia than carried out in previous scientific studies. Next to EHF, the heat wave indices CTN90p and CTX90p were used to study heat wave aspects regarding temperature minimum and maximum series separately. The study 
could improve the understanding in the spatial and temporal characteristics and changes in past summer heat wave events over Georgia. Climatologies across the study area show clear patterns for most of the heat wave aspects. Stations with highest climatological values for HWD, HWF and HWday are located in the Southeast. Highest values for mean HWA and HWM are found in the Southwest of the study area. For $\mathrm{HW}_{\text {sev }}$ and $\mathrm{HW}_{\text {ex }}$ both regions demonstrate highest climatological values. For all aspects lowest heat wave impacts can be expected in central Georgia. The seasonal distribution of $\mathrm{HWday}, \mathrm{HW}_{\text {sev }}$ and $\mathrm{HW}_{\text {ex }}$ between 1961 and 2010 implies the occurrence of highest heat wave intensities in May and September. Highest numbers of high-intensity heat wave days are measured in May, while most low-intensity heat wave days can be found during August. Regarding changes in heat wave events almost all heat wave aspects analyzed based on the indices EHF, CTX90pct and CTN90pct show significant increasing trends in the Georgia-average. However, HWA and HWM show predominantly insignificant and only small changes during the analysis period. HWday and HWF show by far the largest trend magnitudes across all heat wave indices studied (EHF, CTN90pct and CTX90pct), which is consistent with findings of $[11,18]$, stating that occurrence-based heat wave aspects possess larger trend magnitudes. They also found that the high magnitudes of trends for HWF are driving increases in HWN and HWD, due to the fact that the overall number of heat waves (and their duration) will increase when the number of participating days increases. Spatial patterns of trends over Georgia are difficult to assess, which can be attributed to the moderate data quality of several time-series. Nevertheless, it is notable that for the heat wave aspects HWN, HWF, HWD, and HWday the highest proportion of increasing station trends can be observed in the Southeastern and Southwestern region of Georgia. Tbilisi station experienced a pronounced increase in the intensity, frequency and duration of heat waves during 1961 and 2010 compared to the Georgian-average and its neighboring stations. This result corresponds well with findings by [27-30] projecting an increasing number of heat wave events in the EMME region, particularly in urban areas. Including the strong increase in extreme warm night-time temperatures, these results could be explained by the UHI effect, the enhanced heat absorption and storage in sealed surface during the day and the slow release at night, and combined interactions between heat waves and urban heat islands [26,46]. The most severe summer heat waves in Tbilisi have been identified in the years 1971, 1995, 1997, 1998 and 2007. Comparing the indices CTN90pct and CTX90pct, it is shown, that all trends for $\mathrm{T}_{\min }$ (night-time) based events over Georgia increase faster than for days-time events, which corresponds to global heat wave observations [11] and changes for extreme $T_{\min }$ and $\mathrm{T}_{\max }$ events $[16,32,47-49]$. These findings highlight the importance of selecting the appropriate index related to the most affected sector investigated. Heat wave studies based on minimum temperature rather consider impacts on sectors, such as agriculture, whereas temperature maximum-based heat wave indices are appropriately used to determine impacts on infrastructure. However, for investigations on power consumption and human health impacts a heat wave index based on a combination of minimum and maximum temperature might be the most suitable choice. In order to obtain a more detailed insight in the connections of large-scale drivers on the occurrence of heat waves, a further study on contributions of land-atmosphere coupling and large-scale atmospheric circulation over the Caucasus region is necessary. 


\section{Acknowledgments}

This study was supported by the research grant International Postgraduate Studies in Water Technologies (IPSWaT) of the International Bureau, Federal Ministry of Education and Research, Germany (IPS 10/30P2) and the German-Georgian project Amies (Analysing multiple interrelationships between environmental and societal processes in mountainous regions of Georgia) of Volkswagen Stiftung. We highly appreciate the valuable suggestions by the reviewers to improve our paper. We also thank Nato Kutaladze and the National Environmental Agency of Georgia (NEA) for kindly providing metadata. Thanks also go to Alexander Maier for proofreading of the manuscript.

\section{Author Contributions}

Ina Keggenhoff performed the main analysis and wrote the paper; Mariam Elizbarashvili assembled and contributed the observation data and Lorenz King supervised the project. All authors discussed the results and implications of the manuscript.

\section{Appendix}

Stations used for heat wave analysis with station names, WMO code, station coordinates, altitude and the temperature series used in this study.

\begin{tabular}{lllll}
\hline Station Name & WMO Code & North Latitude & East Longitude & Altitude (m) \\
\hline Abastumani & 37503 & 41.72 & 42.83 & 1265 \\
Ahalcihe & 37506 & 41.63 & 42.98 & 982 \\
Akhalkalaki & 37602 & 41.40 & 43.47 & 1716 \\
Ambrolauri & 37308 & 42.52 & 43.13 & 544 \\
Batumi & 37484 & 41.63 & 41.60 & 32 \\
Dedopliskaro & 37651 & 41.50 & 46.10 & 800 \\
Goderdzi Pass & 37507 & 41.60 & 42.50 & 2025 \\
Gori & 37531 & 41.98 & 44.12 & 590 \\
Kashuri & 37417 & 42.00 & 43.60 & 690 \\
Khulo & 37498 & 41.63 & 42.30 & 946 \\
Kobuleti & 37481 & 41.87 & 41.77 & 7 \\
Kutaisi & 37395 & 42.20 & 42.60 & 116 \\
Kvareli & 37563 & 41.97 & 45.83 & 449 \\
Lentekhi & 37295 & 42.77 & 42.72 & 731 \\
Pasanauri & 37432 & 42.35 & 44.70 & 1064 \\
Sachkere & 37403 & 42.35 & 43.40 & 455 \\
Sagaredjo & 37556 & 41.73 & 45.33 & 806 \\
Samtredia & 37385 & 42.18 & 42.37 & 26 \\
Tbilisi & 37546 & 41.68 & 44.95 & 427 \\
Telavi & 37553 & 41.93 & 45.38 & 562 \\
Tsalka & 37537 & 41.60 & 44.07 & 1458 \\
Zemo-Azhara & 37196 & 43.10 & 41.73 & 2037 \\
\hline
\end{tabular}

\section{Conflicts of Interest}

The authors declare no conflict of interest. 


\section{References}

1. Karl, T.R.; Knight, R.W. The 1995 Chicago heat wave: How likely is a recurrence? Bull. Am. Meteor. Soc. 1997, 78, 1107-1119.

2. Trigo, R.; Garia-Herrera, R.; Diaz, J.; Trigo, I.; Valente, M. How exceptional was the early August 2003 heatwave in France? Geophys. Res. Lett. 2005, 32, L10701.

3. Vandentorren, S.; Bretin, P.; Zeghnoun, A.; Mandereau-Bruno, L.; Croisier, A.; Cochet, C.; Ribéron, J.; Siberan, I.; Declercq, B.; Ledrans, M. August 2003 heat wave in France: Risk factors for death of elderly people living at home. Eur. J. Public Health 2006, 16, 583-591.

4. Tong, S.L.; Ren, C.; Becker, N. Excess deaths during the 2004 heatwave in Brisbane, Australia. Int. J. Biometeorol. 2010, 54, 393-400.

5. Anderson, G.B.; Bell, M.L. Heat waves in the United States: Mortality risk during heat waves and effect modification by heat wave characteristics in 43 U.S. communities. Environ. Health Perspect. 2011, 119, 210-218.

6. Ciais, P.; Reichstein, M.; Viovy, N.; Granier, A.; Ogee, J.; Allard, V.; Aubinet, M.; Buchmann, N.; Bernhofer, C.; Carrara, A.; et al. Europe-wide reduction in primary productivity caused by the heat and drought in 2003. Nature 2005, 437, 529-533.

7. Lanning, S.B.; Siebenmorgen, T.J.; Counce, P.A.; Ambardekar, A.A.; Mauromoustakos, A. Extreme nighttime air temperatures in 2010 impact rice chalkiness and milling quality. Field Crops Res. 2011, 124, 132-136.

8. Smoyer-Tomic, K.E.; Kuhn, R.; Hudson, A. Heat wave hazards: An overview of heat wave impacts in Canada. Nat. Hazard 2003, 28, 463-485.

9. IPCC. Climate Change 2013: The Physical Science Basis; Stocker, T.F., Qin, D., Plattner, G.-K., Tignor, M., Allen, S.K., Boschung, J., Nauels, A., Xia, Y., Bex, V., Midgley, P.M., Eds.; Cambridge University Press: Cambridge, UK; New York, NY, USA, 2013.

10. Kharin, V.; Zwiers, F.W.; Zhang, X.; Hegerl, G.C. Changes in temperature and precipitation extremes in the IPCC ensemble of global coupled model simulations. J. Clim. 2007, 20, 1419-1444.

11. Perkins, S.E.; Alexander, L.A.; Nairn, J.R. Increasing frequency, intensity and duration of observed global heatwaves and warm spells. Geophys. Res. Lett. 2012, 39, L20714.

12. IPCC. Climate Change 2014: Impacts, Adaptation, and Vulnerability. Part A: Global and Sectoral Aspects. Contribution of Working Group II to the Fifth Assessment Report of the Intergovernmental Panel on Climate Change; Cambridge University Press: Cambridge, UK; New York, NY, USA, 2014.

13. IPCC. Climate Change 2014: Impacts, Adaptation, and Vulnerability. Part B: Regional Aspects. Contribution of Working Group II to the Fifth Assessment Report of the Intergovernmental Panel on Climate Change; Cambridge University Press: Cambridge, UK; New York, NY, USA, 2014.

14. Meehl, G.A.; Tebaldi, C. More intense, more frequent, and longer lasting heat waves in the $21 \mathrm{st}$ century. Science 2004, 305, 994-997.

15. Seneviratne, S.; Lüthi, D.; Litschi, M.; Schär, C. Landatmosphere coupling and climate change in Europe. Nature 2006, 443, 203-206.

16. Della-Marta, P.M.; Luterbacher, J.; von Weissenfluh, H.; Xoplaki, E.; Brunet, M.; Wanner, H. Summer heat waves over western Europe 1880-2003, their relationship to large-scale forcings and predictability. Clim. Dyn. 2007, 29, 251-275. 
17. Fischer, E.M.; Seneviratne, S.; Lüthi, D.; Schär, C. Contribution of land-atmosphere coupling to recent European summer heat waves. Geophys. Res. Lett. 2007, 34, L06707.

18. Fischer, E.M.; Schär, C. Consistent geographical patterns of changes in high-impact European heatwaves. Nat. Geosci. 2010, 3, 398-403.

19. Kuglitsch, F.G.; Toreti, A.; Xoplaki, E.; Della-Marta, P.M.; Zerefos, C.S.; Türkeş, M.; Luterbacher, J. Heat wave changes in the eastern Mediterranean since 1960. Geophys. Res. Lett. 2010, 37, L04802.

20. Grumm, R.H. The Central European and Russian heat event of July-August 2010. Bull. Am. Meteor. Soc. 2011, 92, 1285-1296.

21. Dole, R.; Hoerling, M.; Perlwitz, J.; Eischeid, J.; Pegion, P.; Zhang, T.; Quan, X.-W.; Xu, T.; Murray, D. Was there a basis for anticipating the 2010 Russian heat wave? Geophys. Res. Lett. 2011, 38, L06702.

22. Shahgedanova, M. Climate at present and in the historical past. In The Physical Geography of Northern Eurasia: Russia and Neighbouring States; Shahgedanova, M., Ed.; Oxford University Press: Oxford, UK, 2002; pp. 70-102.

23. Keggenhoff, I.; Elizbarashvili, M.; King, L. Recent changes in Georgia's temperature means and extremes: Annual and seasonal trends between 1961 and 2010. Weather Clim. Extremes 2014, doi:10.1016/j.wace.2014.11.002.

24. MOE. Georgia's Second National Communication under the United Nations Framework Convention on Climate Change; Ministry of Environment Protection and Natural Resources of Georgia: Georgia, Tbilisi, 2009.

25. Nairn, J.; Fawcett, R. Defining Heatwaves: Heatwave Defined as a Heat-Impact Event Servicing all Community and Business Sectors in Australia; CAWCR Technical Report, No. 060; Centre for Australian Weather and Climate Research: Melbourne, Vic, Australia, 2013.

26. Li, D.; Bou-Zeid, E. Synergistic interactions between urban heat islands and heat waves: The impact in cities is larger than the sum of its parts. J. Appl. Meteor. Climatol. 2013, 52, 2051-2064.

27. Zittis, G.; Hadjinicolaou, P.; Lelieveld, J. Role of soil moisture in the amplification of climate warming in the Eastern Mediterranean and the Middle East. Clim. Res. 2014, 59, 27-37.

28. Zittis, G.; Hadjinicolaou, P.; Fnais, M.; Lelieveld, J. Projected changes in heat wave characteristics in the eastern Mediterranean and the Middle East. Reg. Enironm. Chang. 2015, doi:10.1007/s10113-014-0753-2.

29. Lelieveld, J.; Hadjinicolaou, P.; Kostopoulou, E.; Chenoweth, J.; El Maayar, M.; Giannakopoulos, C.; Hannides, C.; Lange, M.A.; Tanarhte, M.; Tyrlis, E.; et al. Climate change and impacts in the Eastern Mediterranean and the Middle East. Clim. Chang. 2012, 114, 667-687.

30. Lelieveld, J.; Hadjinicolaou, P.; Kostopoulou, E.; Giannakopoulos, C.; Tanarhte, M.; Tyrlis, E. Model projected heat extremes and air pollution in the eastern Mediterranean and Middle East in the twenty-first century. Reg. Environ. Chang. 2013, 14, 1937-1949.

31. Elizbarashvili, E.S.; Tatishvili, M.R.; Elizbarashvili, M.E.; Elizbarashvili, S.E.; Meskhiya, R.S. Air temperature trends in Georgia under global warming conditions. Russ. Meteorol. Hydrol. 2013, 38 , 234-238.

32. Alexander, L.V.; Zhang, X.; Peterson, T.C.; Caesar, J.; Gleason, B.; Klein Tank, A.M.G.; Haylock, M.; Collins, D.; Trewin, B.; Rahimzadeh, F.; et al. Global observed changes in daily climate extremes of temperature and precipitation. J. Geophys. Res. 2006, 111, D05109. 
33. Fischer, E.M.; Lawrence, D.M.; Sanderson, B.M. Quantifying uncertainties in projections of extremes-A perturbed land surface parameter experiment. Clim. Dyn. 2011, 37, 1381-1398.

34. Collins, D.A.; Della-Marta, P.M.; Plummer, N.; Trewin, B.C. Trends in annual frequencies of extremes temperature events in Australia. Aust. Meteor. Mag. 2000, 49, 277-292.

35. Pezza, A.B.; van Rensch, P.; Cai, W. Severe heat waves in southern Australia: Synoptic climatology and large scale connections. Clim. Dyn. 2012, 38, 209-224.

36. Perkins, S.; Alexander, L. On the measurement of heat waves. J. Clim. 2013, 26, 4500-4517.

37. Nairn, J.; Fawcett, R.; Robert, J.B. The Excess Heat Factor: A Metric for Heatwave Intensity and Its Use in Classifying Heatwave Severity. Int. J. Environ. Res. Public Health 2015, 12, 227-253.

38. Langlois, N.; Herbst, J.; Mason, K.; Nairn, J.; Byard, R.W. Using the Excess Heat Factor (EHF) to predict the risk of heat related deaths. J. Forensic Legal Med. 2013, 20, 408-411.

39. Wilson, L.; Morgan, G.; Hanigan, I.; Johnston, F.; Abu-Rayya, H.; Broome, R.; Gaskin, C.; Jalaludin, B. The impact of heat on mortality and morbidity in the Greater Metropolitan Sydney Region: A case crossover analysis. Environ. Health A Glob. Access Sci. Source 2013, 12, 1-14.

40. Wang, X.L. A Quantile Matching Adjustment Algorithm for Gaussian Data Series. Available online: http://etccdi.pacificclimate.org/RHtest/QMadj_Gaussian.pdf (accessed on 20 February 2015).

41. Wang, X.L.; Feng, Y. RHtestsV3. User Manual; Environment Canada: Ottawa, Canada, 2010.

42. Alexander, L.; Yang, H.; Perkins, S. ClimPACT-Indices and Software. User Manual. Available online: http://www.wmo.int/pages/prog/wcp/ccl/opace/opace4/meetings/documents/ ETCRSCI_software_documentation_v2a.doc (accessed on 20 February 2015).

43. Sen, P.K. Estimates of regression coefficient based on Kendall's tau. J. Am. Stat. Assoc. 1968, 63, 1379-1389.

44. Mann, H.B. Non-parametric tests against trend. Econometrica 1945, 13, 245-259.

45. Kendall, M.G. Rank Correlation Methods; Charles Griffin: London, UK, 1975.

46. Taha, H. Urban climates and heat islands: Albedo, evapotransipiration and anthropogenic heat. Energy Build. 1997, 25, 99-103.

47. Vose, R.S.; Easterling, D.R.; Gleason, B. Maximum and minimum temperature trends for the globe: An update through 2004. Geophys. Res. Lett. 2005, 32, L23822.

48. Zhang, X.; Aguilar, E.; Sensoy, S.; Melkonyan, H.; Tagiyeva, U.; Ahmed, N.; Kutaladze, N.; Rahimzadeh, F.; Taghipour, A.; Hantosh, T.H.; et al. Trends in Middle East climate extreme indices from 1950 to 2003. J. Geophys. Res. 2005, 110, D22104.

49. Moberg, A.; Jones, P.D.; Lister, D.; Walther, A.; Alexander, L.V.; Brunet, M.; Chen, D.; Della-Marta, P.M.; Jacobeit, J.; Luterbacher, J.; et al. Indices for daily temperature and precipitation extremes in Europe analysed for the period 1901-2000. J. Geophys. Res. 2006, 111, D22106.

(C) 2015 by the authors; licensee MDPI, Basel, Switzerland. This article is an open access article distributed under the terms and conditions of the Creative Commons Attribution license (http://creativecommons.org/licenses/by/4.0/). 